\title{
Mulheres brasileiras pelos olhos de viajantes italianos
}

\author{
Brazilian women through the eyes of \\ Italian travelers
}

Rejane Penna*

Resumo: Ao lermos as descrições dos viajantes europeus sobre o Brasil, durante o século XIX, percebemos que estereótipos anteriores são reafirmados pelos saberes científicos, partindo da hipótese da excelência da sua cultura e a confirmação de um modelo do que seria realmente o humano e a civilização. Para se ter uma ideia mais aproximada de como esse processo foi efetivado, partiremos de alguns trabalhos que estudaram a italianidade, nas suas diversas manifestações, recortando a descrição feita pelos viajantes italianos sobre um elemento específico, já abordado por diversas pesquisas - a mulher. O tempo é o século XIX; o espaço é o Brasil inteiro. Serão enfocados os relatos, entre outros, do médico italiano Alfonso Lommonaco, "Al Brasile", publicada em Milão, no ano de 1889, do naturalista Ermano Stradelli e de Francesco Ammannati "Um viaggio ai confini del mondo, 1865-1868. Acreditamos que os relatos desses viajantes são também reveladores das atitudes que nos levam a perceber melhor a sociedade e o papel da mulher nela.

Palavras-chave: Mulheres. Identidade. Estereótipos. Ciência.

Abstract: In reading the descriptions of European travelers about Brazil, during the nineteenth century, we realize that stereotypes are reaffirmed by previous scientific knowledge, assuming the excellence of their culture and confirmation of a model that would be really human and civilization. To get a better idea of how this process was accomplished, leave some works that studied the Italian identity in its various manifestations, cutting the description given by the Italian travelers on a specific element, as addressed by several studies - women. Time is of the nineteenth century, the entire space is Brazil. Reports will focus on, among others, the Italian doctor Alfonso Lommonaco, "Al Brasile", published in Milan in 1889, Marcone, a

* Doutora e Mestre em História, Historiógrafa da Secretaria de Estado da Cultura, responsável técnica no Arquivo Histórico do Rio Grande do Sul. Supervisora pelo AHRS do projeto "Memórias Reveladas", coordenado pelo Arquivo Nacional. Membro da Comissão elaboradora do Mestrado Profissional em Memória Social e Bens Culturais e Mestrado Acadêmico em Educação do Centro Universitário La Salle. 
former deputy in the National Parliament entitled "The Italians in Brazil", written in 1877 and Francesco Ammannati "A viaggio ai confini del mondo, 1865-1868".

Keywords: Women. Identity. Stereotypes. Science.

\section{Introdução}

Os relatos de viagens, uma das formas mais antigas de literatura, deram origem a reflexões sobre as diferenças existentes nas sociedades humanas, sendo algo intermediário entre o documento pessoal e o relatório oficial.

No principal presente texto delimita-se a experiência de viagem aos homens do século XIX, herdeiros do Iluminismo, que, de forma sistemática e sem intuitos comerciais como objetivo, colocaram-se em movimento. "Era preciso ver para conceber o mundo, era necessário se deslocar" (Lemes, 1991).

Para Stephen Greenblatt, que também se debruçou sobre narrativas de viagem, seus autores são uma espécie de mediadores, intermediários entre os leitores e os descobridores e conquistadores do Novo Mundo, por intermédio de um sistema de representações, o que permite relacionar o texto ao seu autor e não essencialmente ao intermediação que se cria, a variabilidade de conteúdo e de exposição dota este tipo de literatura de expressivo valor testemunhal, ainda que nem sempre documental já que:objeto que descreve. Dessa forma, o contato não se estabelece efetivamente entre os europeus e o Novo Mundo, mas de agentes munidos de representação que, "ao ser transmitida, relatada, faz com que a visão - e a imaginação que a amplia se transforme em testemunho" (Greenblatt, 2002, p. 202).

Mesmo assim e reconhecendo a espécie de

- ela não está isenta de colocações preconceituosas, da desvalorização da própria identidade (no caso a italianidade), cedendo continuamente à tentação da comparação entre a realidade que se esta observando e a realidade da sociedade de pertencimento de quem observa (Trento, 2008, p. 108).

Pode-se dividir estes viajantes de acordo com as características de suas narrativas, conforme observou Lorelai Kury ${ }^{1}$, afirmando haver dois

KURY, Lorelai. Viagens cientificas, p. 3. Disponível em: <http://catalogos.bn.br/ redememoria/ viacientífica.html>, acessado em: 15 jul. 2011. 
grandes eixos temáticos e interpretativos: a descrição pormenorizada de espécimens e fenômenos particulares e a visão de conjunto das populações e da natureza.

A partir desta forma de olhar, "esperam com seus conselhos e observações contribuir para que haja mudança de comportamento em todas as esferas da vida dos habitantes da província, sendo um guia de civilidade" (Lemes, 1991, p. 8). Também observa que se esses viajantes se deslumbraram com a natureza à sua volta, o mesmo não se deu com a descrição que fizeram da organização social aqui encontrada, destacando que a maioria da população vivia na mais absoluta ignorância, vitimada pela violência dessa estrutura política e sociedade patriarcal escravista (Lemes, 1991, p. 11).

$\mathrm{Na}$ verdade as narrativas também inserem-se como experiência individual do sujeito-viajante às portas da modernidade, em que o percurso para terras longínquas surgia claramente como metáfora da viagem interior, carregada de subjetividade e tentativa de autoconhecimento. Portanto, em suas reflexões, o viajante descrevia a terra estrangeira, classificando tanto paisagens como pessoas em um processo de apropriação discursiva que originava uma configuração nova, porém efetiva de conquista.

Andréa Doré (2002, p. 312), descrevendo as impressões de viajantes italianos sobre a presença portuguesa, cita Leonardo Olschki, num trabalho de grande interesse sobre as componentes do registro dos viajantes; concentra-se na ação do descobridor em oposição à daquele que apenas "encontra" algo diverso. Afirma que a descoberta acontece a partir do momento em que a consciência transforma em pensamento e em palavra o que é visto e, sendo assim, considera importante examinar quais os aspectos naturais e humanos que atraem a atenção dos viajantes.

A questão principal, nesses casos - e são analisados os relatos de Marco Polo e de Cristóvão Colombo -, é identificar a razão da escolha que faz o viajante-narrador do que é digno de ser considerado e descrito; escolha essa que pode ter sua origem nos interesses práticos, na instrução, na educação espiritual, no temperamento do viajante, ou na capacidade de se expressar e de observar.

Identificar a forma como foram apresentadas as terras descobertas e exploradas ajuda a compreender o efeito que essas narrativas tiveram sobre o imaginário e sobre iniciativas futuras dos homens da época.

Tratando-se especificamente do Brasil, ao lermos relatos de viajantes europeus, durante o século XIX, percebemos que os estereótipos anteriores, tais como a indolência, sensualidade desenfreada 
e incapacidade para realizações, dentre outros, são reafirmados pelos saberes ditos científicos, partindo da hipótese da excelência da sua civilização e da confirmação de seus pressupostos de um modelo do que seria realmente o humano e a civilização. Os métodos, porém, variaram - ora especulação, ora mensuração - passo fundamental para o posterior ordenamento e classificação. E aí, se fortalecem os relatos impregnados de saberes relacionados a profissões indissociáveis da ciência, adquirindo um estatuto elevado de veracidade. Segundo Núncia Constantino:

A partir do discurso dos médicos, plenamente aceito e autorizado no período, muitos publicistas ou jornalistas italianos iriam manifestar-se contra a emigração italiana para o Brasil, muitas vezes referenciando as opiniões negativas e citando o nome desses médicos. É o caso de Belli, Macola, Meritani ou Moriconi, que não pouparam palavras impressas para desaconselhar o Brasil como destino para seus conterrâneos. ${ }^{2}$

O que não basta para desestimular a vinda para o Brasil, ao menos para os viajantes, já que paralelamente à disseminação dos relatos de viagem, assiste-se à instituição de uma indústria cultural no bojo da disputa entre cultura erudita e cultura popular de mercado para a qual colaboram a expansão das tipografias e a comercialização de livros em larga escala, estimuladas principalmente pelas inovações tecnológicas que proporcionaram maior rentabilidade e velocidade na impressão; com isso ampliou-se e popularizou-se o número de leitores (Santos, 2005, p. 10).

A valorização da leitura entre camadas populares impulsionou a literatura de ficção do gênero aventura, que sem dúvida influenciou os novos hábitos e aspirações do homem moderno, para os quais muito contribuíram as edições dos diários de expedicionários ou relatos dos que se aventuravam pela América, África ou Ásia.

Quem não tinha meios para realizar grandes viagens podia fazê-las através das páginas dos livros. O Brasil era conhecido, porém ainda fazia parte do novo, na medida em que havia sido pouco investigado pelos parâmetros científicos. Constituiram-se, na verdade, em verdadeiro registro moral na tentativa de conceder ao mundo que descortinavam um padrão de civilidade presente na Europa oitocentista (Santos, 2005, p. 12). 


\section{Breve inventário sobre a visão da mulher pelos viajantes italianos}

Para se ter uma ideia mais aproximada de como esse processo foi efetivado, partiremos de alguns trabalhos que estudaram a italianidade, nas suas diversas manifestações, mapeando a descrição feita pelos viajantes italianos sobre um elemento específico, já abordado por diversas pesquisas - a mulher. O tempo é o século XIX; o espaço é o Brasil.

Por vezes (raramente) não chega a ser negativa a imagem brasileira, mas idealizada, impregnada de referências, mitos e estereótipos construídos na Europa, conforme percebe-se no relato de Verazzano, onde uma visão nostálgica e irrealista dos ameríndios aproxima-os a povos antigos, com representações em que assumem aparência hercúlea ou apolínea, de corpos bem proporcionados como os de deuses gregos e certa "[...] aria dolce e soave imitando molto l'Antico" (Verazzano, 1996, p. 35).

Não sendo propriamente um viajante dentro dos moldes que adotamos, é relevante citar algumas visões sobre a mulher por parte do médico italiano Giovanni Palombini, estudado por Schwartzmann (2007), que entre 1901 e 1914 percorreu o interior do Estado do Rio Grande do Sul, onde, além da prática itinerante da Medicina, escreveu um relato de viagem com diversas observações oriundas desta experiência:

As críticas aos negros são exemplificadas principalmente no comportamento sexual das mulheres que, além de consideradas promíscuas, são partícipes de orgias sexuais. O médico italiano também critica a participação dessas em festividades religiosas, comparando-as com o comportamento recatado das italianas nas mesmas situações (Schwartzmann, 2007, p. 93).

Adiante, a autora analisa que apenas em poucas situações "há um reconhecimento individual de mulheres, com exceção de duas mulheres nominadas na cidade de Jaguarão, além de mencionar outras mulheres apenas nos relatos a centros econômicos importantes do Rio Grande do Sul (Schwartzmann, 2007, p. 115).

Em outro trabalho, no estudo sobre Alfonso Lomonaco: As coisas mais triviais foram classificadas como exóticas e estranhas, destacando-se o trecho sobre o "luxo exagerado na forma como a maioria das mulheres se vestia para circular por essa rua ou ir ao teatro", acrescentando ainda um suposto "gosto do carioca pelos jogos de loteria e do grande número de prostitutas que circulavam pelas ruas", indignando-se com a tolerância que se tinha em relação a elas (Lomonaco, 1890, 2005, p. 22) 
O mesmo viajante, já em Campinas, emite uma das poucas menções positivas, pois o Partido Republicano lhe despertou a atenção, já que, segundo ele, além de possuir um grande número de afiliados, contava com a participação de mulheres e filhas dos ilustres republicanos" (Lomonaco, 2005 p. 24)

Mas as críticas retornam, pois em outro relato, descrito por Núncia Constantino, indiretamente, Alfonso Lomonaco refere-se à mulher, à medida que critica uma das principais atividades femininas - o ato de cozinhar e seus produtos - conforme observa-se no trecho a seguir, comentando o regime alimentar dos brasileiros, que considera primitivo:

A Cozinha é muito simples e que, talvez por isso, as manifestações da vida são mesquinhas e limitadas entre os brasileiros. O prato principal é a feijoada que só o estômago de um croata ou de um lapão poderia tolerar impunemente; ou então come-se o virado, mexido de feijão preto, cebola, banha de porco. Além do mais, come-se sempre a mesma comida, preparada de igual forma. Conclui que tal alimentação, rica em hidrocarbonatos e em gordura, resulta na preguiça que, por sua vez, é decorrente da fartura do país que produz feijão e arroz em quantidade, inibindo a diversificação alimentar. $^{3}$

Passemos ao relato de Marcone, ex-deputado no Parlamento Nacional, intitulado Os italianos no Brasil, escrito em 1877. Chegando ao Rio de Janeiro, suas impressões descrevem uma cidade imunda, espetáculo da degradação da antiga residência de uma corte europeia que se transformara em lupanar. A mulher negra é considerada bela e sensual, caso sejam desconsiderados os parâmetros europeus e valorizadas características de uma certa "pureza de raça":

No Rio-Janeiro, as mulheres indígenas são belas também, mas de uma beleza pouco procurada no grande mercado. E em meio às que não degeneradas por cruzamento, e possuidoras ainda do tipo primitivo da própria raça, há aquelas de belezas verdadeiramente artísticas. Essas possuem o rosto singularmente tatuado, e a cor não mais do negro ébano da costa da África, mas de um bronzeestatuário que as torna interessantes. Encontram-se, a todo instante, feições torneadas, e extraordinariamente grandes; todas de traje,

3 CONSTANTINO, Núncia. Viajantes italianos: imigração, saúde e cidadania. Rivista Digitale Oriundi. Disponível em: <http://oriundi.net/site/>, acessado em: 05 jul. 2011. 
isto é, com o turbante na cabeça, e com uma larga faixa na cintura. Fumam o pequeno cachimbo, e é raro que não carreguem seu filhinho nas costas, seus pezinhos fincados na faixa, as mãozinhas

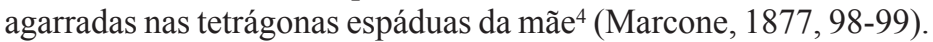

A autora que transcreve a visão de Marcone nos esclarece que inicialmente, poder-se-ia pensar em uma descrição geral da mulher, mas se trata da descrição de negras, únicas mulheres a serem caracterizadas como "brasileiras típicas", praticando a exclusão de uma brasileira branca, semelhante às europeias.

Mais adiante, a mulher aqui já não é mais possuidora daquela beleza estonteante, existindo, inclusive notas relativas a uma mulhermacaco, exotismo típico dos relatos dos séculos XV e XVI, quando os europeus identificam tudo aquilo que desconheciam como estereótipos de figuras exóticas e medonhas, como os gigantes ou pigmeus de certas regiões.

A mulher, na visão dos viajantes, assume uma dupla mitificação, à medida que a aura de mistério que cerca a própria europeia, somam-se as representações construídas sobre o desconhecimento, tanto de paisagens, como de brasileiras. Sobre a condição em que viviam essas mulheres são lançados olhares extremamente críticos em relação à condição social, educação e o papel na família.

\section{Algumas possibilidades de análise}

Para além dos preconceitos e de suas impossibilidades de compreender o que se passava à sua volta, acreditamos que os relatos desses viajantes são também reveladores das atitudes que nos levam não somente a perceber melhor a sociedade e o papel da mulher, mas as possibilidades de relacionamento entre Europa-Brasil, permeada por imaginários que norteariam a dinâmica das relações.

Com a leitura dos relatos desses viajantes italianos é possível afirmar que são extremamente econômicos, tanto nos adjetivos, como nas tentativas de compreensão das mulheres que viram ou deixaram de ver pelos caminhos, povoados e vilas.

Certamente, quando os viajantes se referem à reclusão da mulher no Brasil é a estes espaços de convívio social, fora da casa, que se referem. Talvez nem a reclusão da brasileira tenha sido tão rígida, quanto os $4<$ http://www.letras.ufrj.br/anglo_germanicas/cadernos/numeros/062010/textos/cl
26062010Ana.pdf136>. 
autores deram a entender, nem a situação das mulheres europeias tão diversa quanto à literatura de viagem deixava supor.

É importante avaliar o peso das próprias convicções e experiências precedentes dos viajantes, pois dificilmente modificaram-se e, ao final da jornada, sua imagem de determinado objeto quase sempre correspondeu a sua sensibilidade e à experiência com a qual ele tinha iniciado a viagem,"visto que cada um trazia consigo uma bagagem de ideias, recordações e referências, em poucas palavras de "imagens que se sobrepõem" (Castiglione, 2008, p. 113).

Se ao longo de suas narrativas o cotidiano da sociedade e suas práticas foram vistos com exotismo, acompanhados quase sempre de adjetivos pejorativos, as mulheres não escaparam, desses comentários. Ao se ler os vários relatos deixados pelos viajantes é possível compreender que eles aqui chegavam carregando suas próprias visões a respeito do papel estabelecido para as mulheres. Traziam consigo um ideal de condição feminina, normativo, abstrato, carregado de estereótipos.

Em suma, bem mais do que um descortinar da situação da mulher no Brasil do século XIX, podemos considerar as narrativas desses viajantes europeus, no caso recortados pela nacionalidade italiana, como filosoficamente ligados e condicionados por tudo o que obtiveram da educação clássica, criando, no seu conjunto um filtro de leitura proporcional ao grau de cultura do autor e que obtiveram repercussão à medida que inseriam-se em um período em que muitas pessoas buscavam tornar a América e, por conseguinte, o Brasil em lugar legível, tanto para o viajante que olhava, quanto para aqueles que estavam na Europa e teriam acesso aos seus relatos das viagens.

\section{Referências}

CASTIGLIONE, Arturo. Note in margine a: Um viaggio in America. Milão: Il Rotary, 1938. p. 3. In: TRENTO, Angelo. Os viajantes italianos na América Latina durante o período fascista: entre curiosidade. Locus: revista de história, Juiz de Fora, 2008.

DORÉ, Andréa. Cristãos na Índia no século XVI: a presença portuguesa e os viajantes italianos. Rev. Bras. Hist., São Paulo, v. 22, n. 44, 2002.

GREENBLATT, Stephen. In: DORE, Andréa. Cristãos na Índia no século XVI: a presença portuguesa e os viajantes italianos. Rev. Bras. Hist. [online]. v. 22, n. 44, p. 311-339, 2002.

LEMES, Cláudia Graziela Ferreira Lemes. O olhar sobre a mulher goiana na bagagem dos viajantes. In: BRETAS, Genesco Ferreira: História da instrução pública em Goiás. Editora da Universidade de Goiás, 1991. 
LOMONACO, Dott. Alfonso. Al Brasile. Milano: Società Editrice Libraria, 1890. In: OLIVEIRA, Flavia. A visão de um viajante europeu sobre o Brasil do final do século XIX. Patrimônio e Memória, UNESP-FCLAs-CEDAP, v. 1, n. 2, 2005.

SANTOS, Fabiane Vinente dos. Brincos de ouro, saias de chita: mulher e civilização na Amazônia segundo Elizabeth Agassiz em Viagem ao Brasil (1865-1866). Hist. cienc. saude-Manguinhos [online]. v. 12, n. 1, 2005.

SCHWARTSMANN, Leonor Carolina Baptista. Olhares do Médico-Viajante Italiano: Giovanni Palombini no Rio Grande do Sul (1901-1914). Dissertação (Mestrado) Programa de Pós-Graduação em História da Faculdade de Filosofia e Ciências Humanas, Pontifícia Universidade Católica do Rio Grande do Sul, Porto Alegre, 2007.

TRENTO, Angelo. Os viajantes italianos na América Latina durante o período fascista: entre curiosidade. Locus: revista de história, Juiz de Fora, v. 14, n. 2, p. 105-148, 2008.

VERAZZANO in LEITE, José Roberto Teixeira. Viajantes do imaginário: a América vista da Europa, SÉC. XV-XVII. Revista USP, São Paulo, jun./ago. 1996.

\section{Sites:}

$<$ http://oriundi.net/site/>. Acessado em: 05 jul. 2011. (CONSTANTINO, Núncia. Viajantes italianos: imigração, saúde e cidadania. Rivista Digitale Oriundi).

$<$ http://catalogos.bn.br/redememoria/viacientífica.html>. Acessado em: 15 jul. 2011. (KURY, Lorelai. Viagens cientificas. p. 3).

$<$ http://www.letras.ufrj.br/anglo_germanicas/cadernos/numeros/062010/textos/ cl26062010Ana.pdf136>. (MARCŌNE [1877, p. 98-99]. In: VIEIRA, Ana Thereza Basílio. O olhar dos viajantes italianos sobre o Rio de Janeiro nos séculos XVIII e XIX. Cadernos de Letras, UFRJ, n. 26, jun. 2010). 